\title{
Heart disease and left ventricular rotation - a systematic review and quantitative summary
}

\author{
Aaron A Phillips ${ }^{1,2}$, Anita T Cote ${ }^{2}$, Shannon SD Bredin ${ }^{2}$ and Darren ER Warburton $1,2,3^{*}$
}

\begin{abstract}
Background: Left ventricular (LV) rotation is increasingly examined in those with heart disease. The available evidence measuring LV rotation in those with heart diseases has not been systematically reviewed.

Methods: To review systematically the evidence measuring LV rotational changes in various heart diseases compared to healthy controls, literature searches were conducted for appropriate articles using several electronic databases (e.g., MEDLINE, EMBASE). All randomized-controlled trials, prospective cohort and case-controlled studies that assessed LV rotation in relation to various heart conditions were included. Three independent reviewers evaluated each investigation's quality using validated scales. Results were tabulated and levels of evidence assigned.

Results: A total of 1,782 studies were found through the systematic literature search. Upon review of the articles, 47 were included. The articles were separated into those investigating changes in LV rotation in participants with: aortic stenosis, myocardial infarction, hypertrophic cardiomyopathy, dilated cardiomyopathy, non-compaction, restrictive cardiomyopathy/ constrictive pericarditis, heart failure, diastolic dysfunction, heart transplant, implanted pacemaker, coronary artery disease and cardiovascular disease risk factors. Evidence showing changes in LV rotation due to various types of heart disease was supported by evidence with limited to moderate methodological quality.

Conclusions: Despite a relatively low quality and volume of evidence, the literature consistently shows that heart disease leads to marked changes in LV rotation, while rotational systolic-diastolic coupling is preserved. No prognostic information exists on the potential value of rotational measures of LV function. The literature suggests that measures of LV rotation may aid in diagnosing subclinical aortic stenosis and diastolic dysfunction.
\end{abstract}

Keywords: Systematic review, Ventricular twist, Ventricular torsion, Heart disease

\section{Background}

In recent years, there has been increased interest in quantifying left ventricular (LV) rotation.[1-6] Using basal and apical views of the heart (and occasionally mid-ventricular) the myocardium can be digitally "tagged" (using magnetic resonance imaging (MRI)) or "tracked" (echocardiography), using specialized software, and its motion analyzed. Although a variety of nomenclature exists, most commonly in the literature, LV twist is estimated by calculating the maximal instantaneous difference in rotation between the apical and basal levels

\footnotetext{
* Correspondence: darrenwb@interchange.ubc.ca

${ }^{1}$ Experimental Medicine Program, Faculty of Medicine, University of British

Columbia, Vancouver, Canada

${ }^{2}$ Physical Activity and Chronic Disease Prevention Unit, University of British

Columbia, Vancouver, Canada

Full list of author information is available at the end of the article
}

in the short axis plane. Torsion is calculated by dividing twist by the longitudinal length between the two recorded short-axis levels (ie. LV length). Left ventricular untwist refers to the amount of twist that occurs during diastole $[7,8]$. Echocardiography with tissue tracking and MRI with tissue tagging are the most commonly performed techniques for evaluating these parameters [9-11]. The use of MRI for evaluating rotation of the LV is the considered the most accurate technique and has been shown to correlate well with the tissue Doppler technique[11] and speckle tracking echocardiography (STE) $[9,12]$. It should be noted that a trade-off exists between MRI and STE for the measurement of LV rotation. Although it is considered more accurate, MRI requires considerably more time for acquisition, has less temporal resolution, and is less affordable and accessible in most research and clinical environments. Indeed, the recent

\section{() Biomed Central}


surge in the number of publications evaluating LV rotation has coincided with the arrival of ultrasound tissue tracking [13].

In young healthy individuals, systole of the LV is associated with counterclockwise rotation of the apical level while the basal level rotates clockwise (when viewed from the apex). Rotational motion, according to mathematical models, depends disproportionately on fibers arranged in a helical manner around the LV [14]. It has been suggested that up to $40 \%$ of stroke volume is produced from twisting forces within the LV [6]. Additionally, myocardial energy efficiency is thought to be dependent on LV twist; both by normalizing the fiber shortening of the endocardial and epicardial layers during contraction, and by creating sufficient transmitral pressure to aid in ventricular filling during diastole. Stored energy, in the spring like cardiac protein titin, is considered to be largely influenced by twist [15]. The resulting early untwisting (which primarily occurs before the opening of the mitral valve) beneficially influences early diastolic filling [16]. Left ventricular rotation parameters have been shown to have weak but significant negative correlations to afterload and male gender while possessing a weak positive relationship with heart rate $[17,18]$. Left ventricle rotation is also affected in various heart diseases including but not exclusively: aortic stenosis [19], heart failure [20], cardiomyopathy [21], heart transplant [5], diastolic dysfunction [3], and myocardial infarction (MI) [22]. The purpose of this systematic review is to present a synopsis of the scientific literature investigating the impact of various heart diseases on LV rotation. We feel a review characterizing heart disease related changes in ventricular rotation is necessary to summarize the current trends, as the interest in these measures increases. Our objective is to review systematically the evidence measuring LV rotational changes in various heart diseases compared to healthy controls.

\section{Methods}

A keyword literature search for all scientific publications from 1950 to present investigating the interaction between heart disease and LV rotational parameters was conducted using the following online databases: MEDLINE, EMBASE, Cochrane Library, ACP Journal Club, DARE, CCTR, CMR, HTA, NHSEED, PsycINFO, SPORTDiscus and CINAHL. Heart disease key words heart disease, cardiovascular disease, heart failure, heart transplant, valve stenosis, aortic stenosis, cardiomyopathy, myocardial infarction, transplant - and rotational function keywords - rotation, twisting, untwisting, recoil, twist, torsion, torsional - as well as ventricular anatomy phrases - ventricular, ventricle, heart, cardiac, and myocardial - were paired by permutation (Table 1). A total of 1,782 papers were found after which duplicates,
Table 1 Results of the OVID (MEDLINE, EMBASE, ACP, Cochrane Library, DARE, CCTR, CMP, HTA, NHSEED) literature search

\begin{tabular}{lll}
\hline$\#$ & Searches (18 December 2010) & Results \\
\hline Region of Interest Search Term & \\
\hline 1 & Ventricular & 493973 \\
\hline 2 & Ventricle & 341745 \\
\hline 3 & Heart & 2225277 \\
\hline 4 & Cardiac & 871838 \\
\hline 5 & myocardial & 567273 \\
\hline Rotation Characteristic Search Term & \\
\hline 6 & Rotation & 114762 \\
\hline 7 & Twisting & 4910 \\
\hline 8 & Untwisting & 580 \\
\hline 9 & Recoil & 4625 \\
\hline 10 & Twist & 9589 \\
\hline 11 & Elastic recoil & 2019 \\
\hline 12 & Torsion & 29064 \\
\hline 13 & Torsional & 9246 \\
\hline
\end{tabular}

Heart Disease Search Term

14 Heart disease 334979

15 Cardiovascular disease 205473

16 Heart failure 275006

17 Heart transplant 12545

18 Valve stenosis 59694

19 Aortic stenosis 17785

20 Cardiomyopathy 109271

21 Myocardial infarction 298842

22 Transplant 197267

Combined Region of Interest Search Terms

231 or 2 or 3 or 4 or $5 \quad 2694602$

Combined Rotation Characteristic Search Term

246 or 7 or 8 or 9 or 10 or 11 or 12 or 13 Combined Heart Disease Search Term

2514 or 15 or 16 or 17 or 18 or 19 or 20 or 21 or 22 or 231937593

Combined Population of Interest, Outcome Variable, and Intervention Strategy Search Terms

$26 \quad 23$ and 24 and 25

Please note this does not include the results of the EBSCO (PsychINFO, SPORTDiscuss and CINAHL) literature search.

review papers, letters to the editor, those not in English, those without comparable groups, those examining extremely rare heart diseases, and those not evaluating LV rotational outcomes in human adults were removed from the sample; leaving a total of 40 articles. Seven additional papers [2,5,22-25] were added to the sample as a result of cross referencing, leaving a total of 47 articles (Figure 1).

An evaluation of the methodological quality of each article was completed by two reviewers (AP, AC) and 


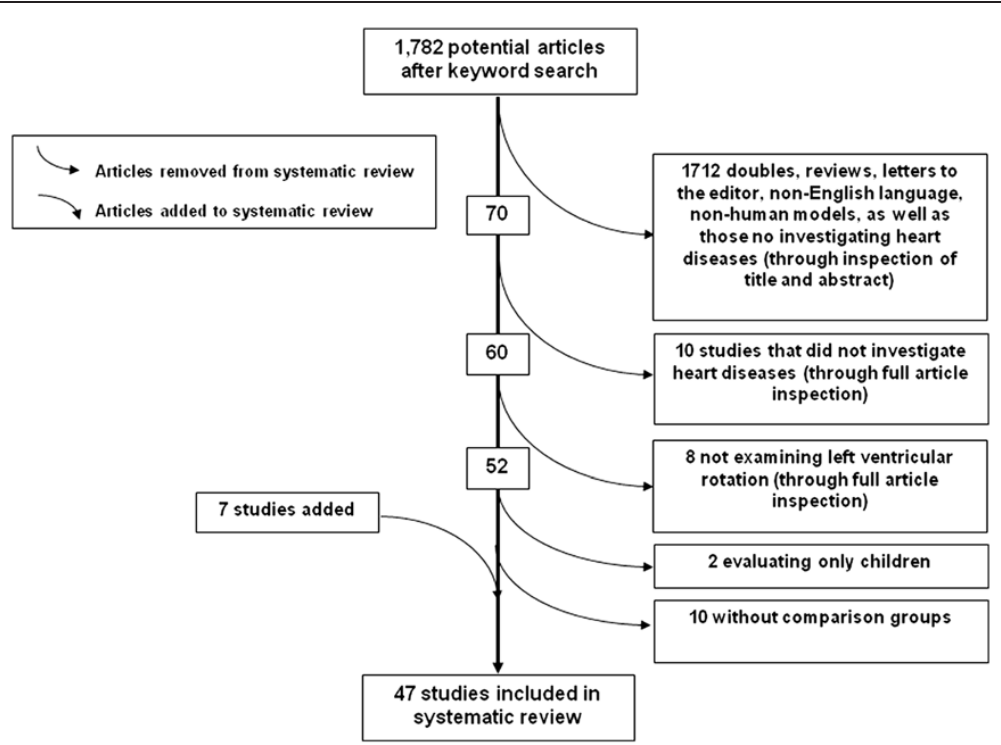

Figure 1 Article decisions - flow of studies through the review.

confirmed by a third reviewer with expertise in systematic reviews (DW) using the Downs and Black (D\&B) tool for non-RCTs [26]. The highest and therefore most methodologically strong score attainable for a given research article is 27 for the D\&B Tool. Higher points indicate a superior methodological quality. Further, the level of evidence was evaluated using a five level scale [26] (simplified form of Sackett) [27] where Level 1 (the highest level of evidence) $=$ RCT with a high methodological quality score; Level $2=$ a RCT with a low methodological quality score, a non-randomized prospective-controlled study, or a cohort study; Level $3=$ a case-control study; Level $4=$ a pre- and post-test or a case series; and Level 5 (the lowest level of evidence) $=$ an observational report or case report with only a single subject [28]. Librarians from the University of British Columbia and all authors approved this systematic process. Ranking scores were performed in duplicate after which any discrepancies were solved by discussion.

Operational definitions were developed to streamline comparisons of primary outcome variables between studies. Rotation was defined as the rotary motion (in degrees) of either the apex, base, or mid-ventricle. Also, as viewed from the apex of the heart, counterclockwise rotation is denoted by a positive angle (degrees) while clockwise rotation is marked by a negative angle (degrees).[29,30] Twist was further defined as the maximal instantaneous basal to apical angle difference (degrees).[31-33] Torsion was then defined as twist divided by end-diastolic LV length (between the two short axis images) (degrees/cm).[7,29,30,34] Mean values for systolic peak rotation, systolic basal rotation, peak systolic twist, twist rate, peak torsion, diastolic peak untwist, untwist rate, and time to peak untwist were recorded from each article which provided data.

Where two or more articles reported mean differences between a given cardiovascular disorder, the average and standard deviation of the percent difference was calculated. These values are presented graphically in a series of figures throughout this article. Percent differences between groups are reported as the difference relative to healthy controls in absolute amplitude. For example, a percent reduction in both a negative rotation at the base and a positive rotation at the apex are both reported as negative values.

\section{Results}

The articles selected were categorized into thirteen groups according to heart disease. Within the text we have provided a summary table where the overall findings from the moderate to strong articles within each heart disease may be found (Table 2). In order to have a general finding presented in the summary table, two or more articles of moderate to strong methodological quality using the same imaging technique must have reported on a given LV rotation parameter. In the online supplement we have provided comprehensive tables for each heart disease group which describes specific details and rankings of each article in order of descending methodological quality.

Heart disease groups include: 1-Aortic Stenosis $(\mathrm{n}=7$, Online Table 3), 2-MI ( $\mathrm{n}=6$, Online Table 4), 3-Hypertrophic Cardiomyopathy (HCM; $\mathrm{n}=11$, Online Table 5), 4-Dilated Cardiomyopathy ( $\mathrm{n}=9$, Online Table 6), 5Non-Compaction ( $\mathrm{n}=2$, Online Table 7), 6-Systolic Heart Failure (SHF; n=5, Online Table 8), 7-Heart Failure 
Table 2 Summary of difference in left ventricular rotation between heart disease patients and healthy controls

\begin{tabular}{|c|c|c|c|c|c|c|c|c|c|c|c|}
\hline Heart Disease & $\begin{array}{l}\text { D\&B Quality Score } \\
\text { Mean (SD) }\end{array}$ & No. Articles & $\begin{array}{l}\text { Sample Size } \\
\text { Mean (SD) }\end{array}$ & $\begin{array}{l}\text { Apical } \\
\text { Rotation } \\
\left({ }^{\circ}\right)\end{array}$ & $\begin{array}{l}\text { Basal } \\
\text { Rotation } \\
\left({ }^{\circ}\right)\end{array}$ & Twist $\left(^{\circ}\right)$ & $\begin{array}{l}\text { Twist } \\
\text { Rate }(\% / s)\end{array}$ & $\begin{array}{l}\text { Torsion } \\
\text { (\%/length) }\end{array}$ & $\begin{array}{l}\text { Untwist } \\
\text { Rate }(\% / s)\end{array}$ & $\begin{array}{l}\text { Time to Peak } \\
\text { Untwist }\end{array}$ & $\begin{array}{l}\text { Reverse } \\
\text { Rotation }\end{array}$ \\
\hline Aortic Stenosis & $\begin{array}{l}\mathrm{STE}=17(2) \\
\mathrm{MRI}=16(1)\end{array}$ & $\begin{array}{l}4 \\
2\end{array}$ & $\begin{array}{l}N=162 \\
N=25\end{array}$ & $\begin{array}{l}{ }_{\uparrow} \\
\uparrow\end{array}$ & ↔ & $\begin{array}{l}\uparrow \\
\uparrow\end{array}$ & $\leftrightarrow / \uparrow$ & $\uparrow$ & & $\overleftrightarrow{\uparrow}$ & \\
\hline Myocardial Infarction & $\begin{array}{l}\mathrm{STE}=19(3) \\
\mathrm{MRI}=15(1)\end{array}$ & $\begin{array}{l}3 \\
3\end{array}$ & $\begin{array}{l}N=129 \\
N=73\end{array}$ & $\begin{array}{l}\downarrow \\
\leftrightarrow / \downarrow\end{array}$ & $\begin{array}{l}\downarrow \\
\leftrightarrow\end{array}$ & $\downarrow$ & & & & $\uparrow$ & \\
\hline Hypertrophic Cardiomyopathy & $\begin{array}{l}\mathrm{STE}=18(3) \\
\mathrm{MRI}=12(1)\end{array}$ & $\begin{array}{l}7 \\
2\end{array}$ & $\begin{array}{l}N=257 \\
N=15\end{array}$ & $\leftrightarrow \leftrightarrow / \downarrow$ & $\stackrel{\uparrow}{\leftrightarrow}$ & $\downarrow / \leftrightarrow / \uparrow$ & & & $\leftrightarrow$ & $\leftrightarrow / \uparrow$ & \\
\hline Dilated Cardiomyopathy & $\mathrm{STE}=19(1)$ & 6 & $N=294$ & $\downarrow$ & $\downarrow$ & $\downarrow$ & & $\downarrow$ & $\downarrow$ & $\uparrow$ & Yes \\
\hline Non-compaction & $\mathrm{STE}=18(1)$ & 2 & $N=30$ & $\downarrow$ & $\leftrightarrow$ & $\downarrow$ & $\downarrow$ & $\downarrow$ & & & Yes \\
\hline Heart Failure & $\mathrm{STE}=21(3.5)$ & 3 & $N=149$ & $\downarrow$ & $\downarrow$ & $\downarrow$ & & & & & Yes \\
\hline Diastolic Dysfunction & $\mathrm{STE}=20(2)$ & 6 & $N=347$ & $\leftrightarrow$ & $\leftrightarrow / \uparrow$ & $\leftrightarrow$ & $\uparrow$ & & & $\leftrightarrow$ & \\
\hline
\end{tabular}

$\mathrm{N}$; total number of subjects in heart disease group from all publications in group, D \& B; Downs and Black score, MRl; magnetic resonance imaging, 2D-STE; two dimensional speckle tracking echocardiography, $\uparrow$; significant increase in heart disease group as compared to healthy controls, $\downarrow$ significant decrease in heart disease group as compared to healthy controls, $\leftrightarrow$. Note that for HCM, we did not report the two articles

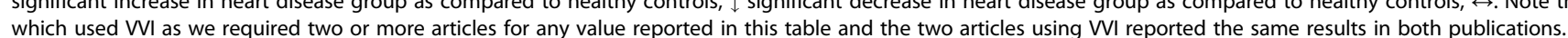

Table 3 Difference in left ventricular rotational parameters between participants with aortic stenosis as compared to healthy controls

\begin{tabular}{|c|c|c|c|c|c|c|c|c|c|}
\hline Study Details & $\begin{array}{l}\text { Matched } \\
\text { Controls }\end{array}$ & $\begin{array}{l}\text { Apical } \\
\text { Rotation }\end{array}$ & $\begin{array}{l}\text { Basal } \\
\text { Rotation }\end{array}$ & Twist & Torsion & $\begin{array}{l}\text { Twist } \\
\text { Rate }\end{array}$ & $\begin{array}{l}\text { Peak } \\
\text { Untwist Rate }\end{array}$ & $\begin{array}{l}\text { Time to } \\
\text { Peak Untwist }\end{array}$ & Additional Notes \\
\hline $\begin{array}{l}\text { Popescu et al. } 2010 \text { Case-control Level } 3 \\
\text { D\&B }=19 \text { 2D-STE** }\end{array}$ & No & $\uparrow$ & $\leftrightarrow$ & $\uparrow$ & $\uparrow$ & $\uparrow$ & $\leftrightarrow$ & $\leftrightarrow$ & $\begin{array}{l}\text { Time to peak apical untwisting rate was longer } \\
\text { in those with aortic stenosis. }\end{array}$ \\
\hline $\begin{array}{l}\text { Tzemos et al. } 2008 \text { Case-control Level } 3 \\
\mathrm{D} \& \mathrm{~B}=19 \text { 2D-WI * }\end{array}$ & Yes & & & $\uparrow$ & & & & & Sample comprised of women. \\
\hline $\begin{array}{l}\text { Stuber et al. } 1999 \text { Case-control Level } 3 \\
\text { D\&B=17 MRI Tagging }\end{array}$ & No & $\uparrow$ & & $\uparrow$ & $\uparrow$ & & & $\uparrow$ & $\begin{array}{l}\text { Time to peak apical untwisting velocity was } \\
\text { increased in those with aortic stenosis. }\end{array}$ \\
\hline $\begin{array}{l}\text { Van Dalen et al. 2011Case-controlLevel } 3 \\
\text { D\&B = 162D-STE*** }\end{array}$ & Yes & $\uparrow$ & $\leftrightarrow$ & $\uparrow$ & & $\leftrightarrow$ & $\uparrow$ & $\uparrow$ & \\
\hline $\begin{array}{l}\text { Carasso et al. } 2009 \text { Case-control Level } 3 \\
\text { D\&B=15 2D-STE* }\end{array}$ & Yes & & & $\downarrow$ & & & & & Aortic stenosis compared to healthy controls. \\
\hline $\begin{array}{l}\text { Nagel et al. } 2000 \text { Case-control Level } 3 \\
\text { D\&B }=15 \text { MRI Tagging }\end{array}$ & No & $\uparrow$ & $\downarrow$ & $\uparrow$ & & & $\downarrow$ & $\uparrow$ & \\
\hline $\begin{array}{l}\text { Sandstede et al. } 2002 \text { Case-control Level } 3 \\
\text { D\&B }=13 \text { MRI Tagging }\end{array}$ & Yes & $\uparrow$ & $\leftrightarrow$ & $\uparrow$ & & & & & \\
\hline
\end{tabular}




\section{Table 4 Difference in left ventricular rotational parameters between participants with prior myocardial infarction as compared to healthy controls}

\begin{tabular}{|c|c|c|c|c|c|c|c|c|c|}
\hline Study Details & $\begin{array}{l}\text { Matched } \\
\text { Controls }\end{array}$ & $\begin{array}{l}\text { Apical } \\
\text { Rotation }\end{array}$ & $\begin{array}{l}\text { Basal } \\
\text { Rotation }\end{array}$ & Twist & Torsion & $\begin{array}{l}\text { Twist } \\
\text { Rate }\end{array}$ & $\begin{array}{l}\text { Time to } \\
\text { Peak Twist }\end{array}$ & $\begin{array}{l}\text { Time to Peak } \\
\text { Untwist }\end{array}$ & Additional Notes \\
\hline $\begin{array}{l}\text { Govind et al. } 2010 \text { Case-control Level } 3 \\
\mathrm{D} \& \mathrm{~B}=23 \text { 2D-STE*** }\end{array}$ & Yes & $\downarrow$ & $\downarrow$ & $\downarrow$ & & & & & $\begin{array}{l}\text { Participants with } \mathrm{Ml} \text { and normal } \mathrm{EF}(>40 \%) \text { had elevated } \\
\text { twist and apical rotation rate as compared to participants } \\
\text { with } \mathrm{Ml} \text { and low } \mathrm{EF}(<40 \%) \text {. }\end{array}$ \\
\hline $\begin{array}{l}\text { Bansal et al. } 2008 \text { Case-control Level } 3 \\
\text { D\&B=17 2D-STE** }\end{array}$ & No & $\downarrow$ & $\downarrow$ & & $\downarrow$ & & & & $\begin{array}{l}\text { Increasing number of infarcts was related to decreased } \\
\text { basal rotation and torsion but not apical rotation. }\end{array}$ \\
\hline $\begin{array}{l}\text { Takeuchi et al. } 2007 \text { Case-control Level } 3 \\
\text { D\&B }=17 \text { 2D-STE** }\end{array}$ & Yes & $\leftrightarrow / \downarrow$ & $\leftrightarrow$ & $\leftrightarrow / \downarrow$ & & $\leftrightarrow / \downarrow$ & $\leftrightarrow$ & $\leftrightarrow / \uparrow$ & $\begin{array}{l}\text { Anterior MI participants were divided into those with normal } \\
(\geq 45 \%) \text { and reduced }(<45 \%) \text { EF. Only reduced EF participants } \\
\text { had reduced twist and apical rotation as well as time to peak } \\
\text { untwist as compared to controls. }\end{array}$ \\
\hline $\begin{array}{l}\text { Nagel et al. } 2000 \text { Case-control Level } 3 \\
\text { D\&B }=15 \text { MRI Tagging }\end{array}$ & No & $\downarrow$ & $\leftrightarrow$ & & & & $\leftrightarrow$ & $\uparrow$ & $\begin{array}{l}\text { Apical rotation is reduced in those with anterolateral MI but } \\
\text { no difference between groups in mid level or basal rotation } \\
\text { occurred. In a subgroup of anterolateral Ml participants with } \\
\text { accompanying LV aneurism, there is a complete loss of apical } \\
\text { rotation and a reversal of mid level rotation that rotates with } \\
\text { the base instead of the apex as in healthy controls. }\end{array}$ \\
\hline $\begin{array}{l}\text { Garot et al. } 2002 \text { Case-control Level } 3 \\
\text { D\&B = } 15 \text { MRI Tagging }\end{array}$ & No & & & & & & & & $\begin{array}{l}\text { Only mid-ventricle (between apex and base) rotation was reported. } \\
\text { Mid-ventricle rotation was reduced in those with MI. Those with } \\
\text { normal EF }(>48 \%) \text { had higher rotation than those with } \\
\text { low } \mathrm{EF}(<48 \%) \text {. }\end{array}$ \\
\hline $\begin{array}{l}\text { Setser et al. } 2007 \text { Case-control Level } 3 \\
\text { D\&B }=14 \text { MRI Tagging }\end{array}$ & No & $\leftrightarrow$ & $\leftrightarrow$ & $\downarrow$ & & & & & Ischemic cardiomyopathy/Ml compared to healthy controls. \\
\hline
\end{tabular}

D \& B; Downs and Black score, MRI; magnetic resonance imaging, 2D-STE; two dimensional speckle tracking echocardiography, ${ }^{* * *}$ indicates that mitral leaflets and luminal obliteration were used for identifying the basal and apical images respectively, ${ }^{* *}$ indicates that mitral leaflets and location inferior to papillary muscle were used for identifying the basal and apical images respectively, LV; left ventricle, EF; ejection fraction, $\uparrow$; significant increase in heart disease group as compared to healthy controls, $\downarrow$ significant decrease in heart disease group as compared to healthy controls, $\leftrightarrow$; no significant difference between heart disease group as compared to healthy controls. 
Table 5 Difference in left ventricular rotational parameters between participants with hypertrophic cardiomyopathy compared to healthy controls

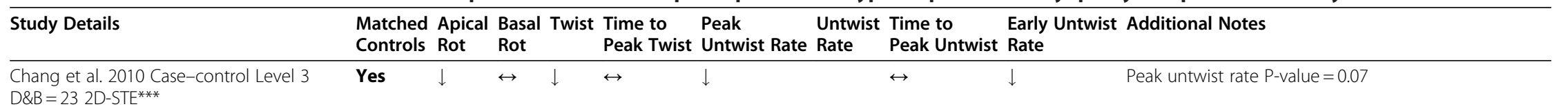
$\mathrm{D} \& \mathrm{~B}=23$ 2D-STE***

Buakhamsri et al. 2009 Case-control Level 3 Yes $\mathrm{D} \& \mathrm{~B}=19$ 2D-STE***

van Dalen et al. 2009 Case-control Level 3 Yes $\mathrm{D} \& \mathrm{~B}=18$ 2D-STE***

Carasso et al. 2010 Case-control Level 3 $\mathrm{D} \& \mathrm{~B}=182 \mathrm{D}-\left.\mathrm{W}\right|^{* *}$

Carasso et al. 2008 Case-control Level 3

Yes

$\leftrightarrow$

$\mathrm{D} \& \mathrm{~B}=18$ 2D-W/**

Wang et al. 2009 Case-control Level 3

$\mathrm{D} \& \mathrm{~B}=17$ 2D-STE***

Yes

Notomi et al. 2006 PCT Level 2

$\mathrm{D} \& \mathrm{~B}=17$ 2D-STE***

Yes

van Dalen et al. 2009 Case-control Level 3 Yes $\mathrm{D} \& \mathrm{~B}=172 \mathrm{D}-\mathrm{STE}^{* * *}$

Abozguia et al. 2010 Case-control Level 3 $\mathrm{D} \& \mathrm{~B}=14$ 2D-STE**

Maier et al. 1992 Case-control Level 3

$\mathrm{D} \& \mathrm{~B}=13 \mathrm{MRI}$ Tagging

Young et al. 1994 Case-control Level 3

$\mathrm{D} \& \mathrm{~B}=10 \mathrm{MR}$ T Tagging
HCM were separated into groups with either sigmoida or reverse septal morphology. Both sub-groups had increased basal rotation. Only the sigmoidal group had increased apical rotation and twist.

Twist time was reduced and untwist time increased in those with HCM.

Mid-level rotation was in the opposite direction as compared to healthy controls (clockwise instead of counter clockwise).

Time to untwisting was lowest in controls, elevated in HCM group and increased again in hypertrophic obstructive cardiomyopathy group.

At rest, no significant differences were reported. During exercise, peak untwisting velocity and peak systolic twist increased in control group but not in HCM group.

Similar to above, HCM were separated into groups with either sigmoidal or reverse septal morphology. Both sub-groups had increased basal rotation. Only the sigmoidal group had increased apical rotation and twist.

In those with non-obstructive HCM there was a delay in reaching $25 \%$ untwist.

Twist was calculated by subtracting the base rotation from apical rotation.

D \& B; Downs and Black score, MRl; magnetic resonance imaging, 2D-STE; two dimensional speckle tracking echocardiography, 2D-VVl; two dimensional velocity vector imaging, *** indicates that mitral leaflets and luminal obliteration were used for identifying the basal and apical images respectively, ${ }^{* *}$ indicates that mitral leaflets and location inferior to papillary muscle were used for identifying the basal and apical images respectively, Apical Rot; apical rotation, Basal Rot; basal rotation, HCM; hypertrophic cardiomyopathy. $\uparrow$; significant increase in heart disease group as compared to healthy controls, $\downarrow$ significant decrease in heart disease group as compared to healthy controls, ↔; no significant difference between heart disease group as compared to healthy controls. 
Table 6 Difference in left ventricular rotational parameters between participants with dilated cardiomyopathy as compared to healthy controls

\begin{tabular}{|c|c|c|c|c|c|c|c|}
\hline \multirow[t]{2}{*}{ Study Details } & \multicolumn{5}{|c|}{ Matched Apical Basal Twist Torsion Time to } & \multicolumn{2}{|c|}{ Peak Untwist Untwist } \\
\hline & Controls & Rot & Rot & & Peak Twist & t Rate & Rate \\
\hline $\begin{array}{l}\text { Buakhamsri et al. } 2009 \text { Case-control Level } 3 \\
\text { D\&B=19 2D-STE*** }\end{array}$ & No & & & & & & $\downarrow$ \\
\hline $\begin{array}{l}\text { van Dalen et al. } 2010 \text { Case-control Level } 3 \\
\text { D\&B }=19 \text { 2D-STE*** }\end{array}$ & Yes & $\downarrow$ & $\leftrightarrow$ & $\downarrow$ & & $\downarrow$ & $\downarrow$ \\
\hline $\begin{array}{l}\text { Liu et al. } 2010 \text { Case-control Level } 3 \\
D \& B=192 D-\left.W\right|^{* * *}\end{array}$ & Yes & $\downarrow$ & $\downarrow$ & $\downarrow$ & $\downarrow$ & & $\downarrow$ \\
\hline $\begin{array}{l}\text { Popescu et al. } 2009 \text { Case-control Level } 3 \\
\text { D\&B } 19 \text { 2D-STE** }\end{array}$ & No & $\downarrow$ & $\downarrow$ & & $\downarrow$ & & \\
\hline
\end{tabular}

\section{Additional Notes}

Peak Untwist

DCM separated into sub-groups who had either a wide or

narrow QRS complex. Narrow-QRS group had reduced untwisting velocity as compared to controls while wide-QRS complex had a further reduced untwisting velocity.

DCM were separated into sub-groups who had normal or reversed apical rotation. Torsion was lower in those with normal rotation compared to controls. Torsion was further reduced in those with opposite apical rotation (essentially torsion was lost). Basal rotation was not different between the two DCM groups. 31/50 participants had opposite rotation at either the base or the apex.

Meluzin et al. 2009 Case-control Level 3 $\mathrm{D} \& \mathrm{~B}=18$ 2D-STE**

Saito et al. 2009 Case-control Level 3 $\mathrm{D} \& \mathrm{~B}=18$ 2D-STE**

Kanzaki et al. 2006 Case-control Level 3 D\&B = 17 MRI Tagging

Yes $\quad \downarrow \quad \downarrow \quad \downarrow \quad \downarrow$

18/37 participants had opposite rotation of either the apex or base. van Dalen et al. 2008 Case-control Level 3 Yes $\mathrm{D} \& \mathrm{~B}=17$ 2D-STE ${ }^{* * *}$

Sade et al. 2008 Case-control Level 3 $\mathrm{D} \& \mathrm{~B}=15$ 2D-STE**

No

$\downarrow$

$\downarrow$

$\leftrightarrow$

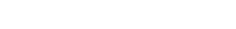

$\downarrow \quad \downarrow \quad \downarrow \quad \uparrow$

D \& B; Downs and Black score, MRl; magnetic resonance imaging, 2D-STE; two dimensional speckle tracking echocardiography, 2D-VVl; two dimensional velocity vector imaging, ***indicates that mitral leaflets and luminal obliteration were used for identifying the basal and apical images respectively, **indicates that mitral leaflets and location inferior to papillary muscle were used for identifying the basal and apical images respectively, Apical Rot; apical rotation, Basal Rot; basal rotation, DCM; dilated cardiomyopathy, $\uparrow$; significant increase in heart disease group as compared to healthy controls, $\downarrow$ significant decrease in heart diseas group as compared to healthy controls, $\leftrightarrow$; no significant difference between heart disease group as compared to healthy controls.

In those with DCM, the apex turned with the base at mid-systole and did not rotate counter clockwise throughout contraction as in healthy controls.

DCM separated into sub-groups who had either ischemic or non-ischemic disease. Both groups had similar LV rotation characteristics. 15/34 participants had opposite rotation at characteristics. $15 / 34$ participar
either the base or the apex. 
Table 7 Difference in left ventricular rotational parameters between participants with various cardiovascular risk factors, right ventricle apical pacing, noncompaction, transplants, coronary artery disease, restrictive cardiomyopathy and constrictive pericarditis as compared to healthy controls

\begin{tabular}{lllllllll}
\hline Study Details & $\begin{array}{l}\text { Matched } \\
\text { Controls }\end{array}$ & $\begin{array}{l}\text { Apical } \\
\text { Rot }\end{array}$ & $\begin{array}{l}\text { Basal } \\
\text { Rot }\end{array}$ & Twist & $\begin{array}{l}\text { Twist } \\
\text { Rate }\end{array}$ & $\begin{array}{l}\text { Time to } \\
\text { Peak Twist }\end{array}$ & $\begin{array}{l}\text { Peak } \\
\text { Untwist Rate }\end{array}$ & $\begin{array}{l}\text { Untwist } \\
\text { Rate }\end{array}$ \\
\hline
\end{tabular}

Sengupta et al. 2008 Case-control Level 3

$\mathrm{D} \& \mathrm{~B}=202 \mathrm{D}-\mathrm{STE} \mathrm{E}^{* *}$

Yes

Sengupta et al. 2008 Case-control Level 3 $\mathrm{D} \& \mathrm{~B}=20$ 2D-STE**

Paetsch et al. 2005 Case-control Level 3

Yes $\leftrightarrow$ $\leftrightarrow$

$\leftrightarrow$

Yes

$\leftrightarrow \quad \downarrow$

D\&B $=19$ MRI Tagging

Delgado et al. 2009. PCT Level 2

$\mathrm{D} \& \mathrm{~B}=18$ 2D-STE***

Mizuguchi et al. 2008 Case-control Level 3 $\mathrm{D} \& \mathrm{~B}=17$ 2D-STE**

van Dalen et al. 2008 Case-control Level 3 $\mathrm{D} \& \mathrm{~B}=17$ 2D-STE***

Bellavia et al. 2010 Case-control Level 3 $\mathrm{D} \& \mathrm{~B}=19$ 2D-STE***

Esch et al. 2009 Case-control Level 3 $\mathrm{D} \& \mathrm{~B}=14$ 2D-STE**
Yes

Yes

Yes

Yes

Yes

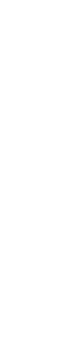

s

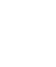

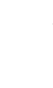

$\leftrightarrow / \downarrow$

$\downarrow \downarrow \downarrow$

$\downarrow$

Restrictive cardiomyopathy did not have significantly different torsion compared to healthy controls.

Apical rotation rate, twist and torsion was reduced in those with constrictive pericarditis.

Measures were not taken at rest. Measures were collected during low or high doses of dobutamine. At both doses, those with coronary heart disease had reduced measures as compared to controls. Increased time to untwist was reported in clinical population.

Right ventricle apical pacing compared to healthy controls.

$\leftrightarrow \quad$ Various cardiovascular risk factors compared to healthy controls.

In all non-compaction participants, the base and apex rotated in the same direction. Those with clockwise rotation had opposite (reduced) apical rotation but normal basal rotation. Those with counter clockwise rotation had reduced apical rotation and opposite (increased) basal rotation.

Non-compaction with normal EF ( $\geq 50 \%)$ was not different in basal rotation from healthy controls whereas those with low EF $(<50 \%)$ had reduced basal rotation.

Heart transplants regress to recipient matched rotation characteristics (instead of maintaining donor age matched rotation). Compared to recipient matched controls, heart transplants had reduced untwisting response to exercise. Both recipient age matched controls and transplant recipients had reductions in twist with exercise whereas donor matched had increased twist with exercise.

\footnotetext{
D \& B; Downs and Black score, MRl; magnetic resonance imaging, 2D-STE; two dimensional speckle tracking echocardiography, EF; ejection fraction, ***indicates that mitral leaflets and luminal obliteration were used for identifying the basal and apical images respectively, **indicates that mitral leaflets and location inferior to papillary muscle were used for identifying the basal and apical images respectively $\uparrow$; significant increase in heart disease group as compared to healthy controls, $\downarrow$ significant decrease in heart disease group as compared to healthy controls, $\leftrightarrow$; no significant difference between heart disease group as compared to healthy controls.
} 
Table 8 Difference in left ventricular rotational parameters between participants with heart failure as compared to healthy controls

\begin{tabular}{|c|c|c|c|c|c|}
\hline Study Details & $\begin{array}{l}\text { Matched } \\
\text { Controls }\end{array}$ & $\begin{array}{l}\text { Apical } \\
\text { Rotation }\end{array}$ & $\begin{array}{l}\text { Basal } \\
\text { Rotation }\end{array}$ & Twist & $\begin{array}{l}\text { Additional } \\
\text { Notes }\end{array}$ \\
\hline $\begin{array}{l}\text { Zhang et al. } 2008 \text { Case-control Level } 3 \\
\text { D\&B =23 2D-STE* }\end{array}$ & Yes & $\downarrow$ & $\downarrow$ & $\downarrow$ & \\
\hline $\begin{array}{l}\text { Bertini et al. } 2009 \text { Case-control Level } 3 \\
D \& B=23 \text { 2D-STE** }\end{array}$ & Yes & $\downarrow$ & $\downarrow$ & $\downarrow$ & \\
\hline $\begin{array}{l}\text { Fuchs et al. } 2004 \text { Case-control Level } 3 \\
D \& B=23 \text { MRI Tagging }\end{array}$ & No & $\downarrow$ & $\downarrow$ & & $\begin{array}{l}\text { Diastolic basal rotation was similar } \\
\text { between controls and those with } \\
\text { heart failure. Diastolic apical rotation } \\
\text { was reduced in those with heart failure. }\end{array}$ \\
\hline $\begin{array}{l}\text { Russel et al. } 2009 \text { Case-control Level } 3 \\
D \& B=18 \text { MRI Tagging }\end{array}$ & No & & & $\downarrow$ & $\begin{array}{l}\text { 20/34 participants with heart failure had } \\
\text { reversed rotation patterns whereas no } \\
\text { healthy controls did. }\end{array}$ \\
\hline $\begin{array}{l}\text { Wang et al. } 2008 \text { Case-control Level } 3 \\
\text { D\&B=17 2D-STE* }\end{array}$ & No & & & $\downarrow$ & \\
\hline
\end{tabular}

D \& B; Downs and Black score, MRI; magnetic resonance imaging, 2D-STE; two dimensional speckle tracking echocardiography, ${ }^{* *}$ indicates that mitral leaflets and location inferior to papillary muscle were used for identifying the basal and apical images respectively, * indicates that land marking for short axis images was not a widely accepted technique or poorly described, $\uparrow$; significant increase in heart disease group as compared to healthy controls, $\downarrow$ significant decrease in heart disease group as compared to healthy controls, $\leftrightarrow$; no significant difference between heart disease group as compared to healthy controls.

Normal Ejection Fraction/Diastolic Dysfunction (HFnEF) ( $\mathrm{n}=6$, Online Table 9), 8-Heart Transplant ( $\mathrm{n}=1$, Online Table 7), 9-Implanted Pacemaker ( $\mathrm{n}=1$, Online Table 7), 10-Cardiovascular Disease Risk Factors $(\mathrm{n}=1$, Online Table 7), 11-Restrictive Cardiomyopathy/Constrictive Pericarditis, $(\mathrm{n}=1$, Online Table 7) and 12-Coronary Artery Disease ( $\mathrm{n}=1$, Online Table 7). Groups 8-12 were discussed in combination as each consisted of only one published article. Note that one paper examined both hypertrophic and dilated cardiomyopathy [35], another both non-compaction and dilated cardiomyopathy [36], another heart failure and diastolic dysfunction [20], while an additional paper investigated both diastolic dysfunction and cardiovascular disease risk factors with no overt disease [37]. All articles, except one prospective control trial in the HCM section [25] were of the case control design (level 3 evidence). The D\&B Tool scores ranged from 9-23 out of 27 (limited to strong methodological strength) [38-40]. Standardizing the location where short axis basal and apical images are located is an important consideration. Although this is not commonly a concern with MRI, as image location can be chosen very accurately, ultrasound collection of the apical location in particular is a challenging task. Only one article reviewed here reported collecting the superior short axis image in a non-traditional location (papillary muscle level) [41]. Further to this, three others simply did not describe their locations (although they were referred to as basal and apical) $[20,42,43]$. In light of this, we feel the short axis ultrasound image locations were well standardized within the literature. Finally, although a small number of articles do not explicitly state the position of the participants during collection, the vast majority report image acquisition occurring while the participant is resting in the supine or lateral decubitus position.

\section{Aortic stenosis \\ Systolic parameters}

Of the seven moderate strength papers (D\&B scores ranged from 15-19) to report on LV rotation in those with aortic stenosis, six papers showed agreement that LV twist is elevated (Online Figure 2). The lone paper that reported reduced LV twist in those with aortic stenosis was removed from this analysis as the authors chose to use a modified technique examining twist relative to the mid-ventricular instead of the basal level [41]. Left ventricular torsion was investigated in two of the strongest quality articles; both showing an elevation as compared to healthy controls (Online Figure 2) $[8,44]$. Also, five moderate quality papers reported on the maximal apical rotation in those with aortic stenosis, all showing increased apical rotation as compared to healthy controls [8,44-47]. Of the four papers that reported individual basal rotation, three reported no change in basal rotation $[8,45,47]$ while one of the lower quality articles showed a reduction [46].

\section{Diastolic parameters}

There was significant disagreement in the literature regarding peak untwist rate in those with aortic stenosis, as increases [47], decreases [46] and no differences were reported (Online Figure 2) [8]. This disagreement is likely related to poorly matched controls, as other than the article from van Dalen, which showed an increase in peak untwist rate, the two remaining articles in this group had control participants that were on average 20 and 30 years younger than patients $[8,46]$. Taken 
Table 9 Difference in left ventricular rotational parameters between participants with diastolic dysfunction as compared to healthy controls

\begin{tabular}{|c|c|c|c|c|c|c|c|c|c|c|}
\hline & $\begin{array}{l}\text { Matched } \\
\text { Controls }\end{array}$ & $\begin{array}{l}\text { Apical } \\
\text { Rotation }\end{array}$ & $\begin{array}{l}\text { Basal } \\
\text { Rotation }\end{array}$ & Twist & Torsion & $\begin{array}{l}\text { Twist } \\
\text { Rate }\end{array}$ & $\begin{array}{l}\text { Time to Peak } \\
\text { Twist }\end{array}$ & $\begin{array}{l}\text { Peak } \\
\text { Untwist Rate }\end{array}$ & $\begin{array}{l}\text { Untwist } \\
\text { Rate }\end{array}$ & $\begin{array}{l}\text { Time to } \\
\text { Peak Untwist }\end{array}$ \\
\hline
\end{tabular}

Wang et al. 2008 Case-control Level 3

$\leftrightarrow$ Untwist Rate Rate Peak Untwist

$\mathrm{D} \& B=23$ 2D-STE*

Perry et al. 2008 Case-control Level 3

No

$D \& B=20$ 2D-STE**

Phan et al. 2009 Case-control Level 3 $\mathrm{D} \& \mathrm{~B}=20$ 2D-STE**

Jang et al. 2009 Case-control Level 3 $\mathrm{D} \& \mathrm{~B}=202 \mathrm{D}-\mathrm{STE} \mathrm{E}^{* * *}$

No D\&B= 20 2D-STE*

Park et al. 2008 Case-control Level 3 $\mathrm{D} \& \mathrm{~B}=19$ 2D-STE***

Mizuguchi et al. 2008 Case-control

Yes

Yes $\uparrow \uparrow \uparrow$

$\uparrow \leftrightarrow$

$\uparrow$

$\uparrow$

$\uparrow / \downarrow$

$\leftrightarrow$

Level 3 D\&B $=17$ 2D-STE**

D \& B; Downs and Black score, MRl; magnetic resonance imaging, 2D-STE; two dimensional speckle tracking echocardiography, ***indicates that mitral leaflets and luminal obliteration were used for identifying the

axis images was not a widely accepted technique or poorly described, E/A ratio; ratio of peak velocity of early filling to peak velocity of late filling, E/E' ratio; ratio of mitral peak velocity of early filling to early diastolic

mitral annular velocity, $\uparrow$; significant increase in heart disease group as compared to healthy controls, $\downarrow$ significant decrease in heart disease group as compared to healthy controls, $\leftrightarrow$; no significant difference

between heart disease group as compared to healthy controls. 


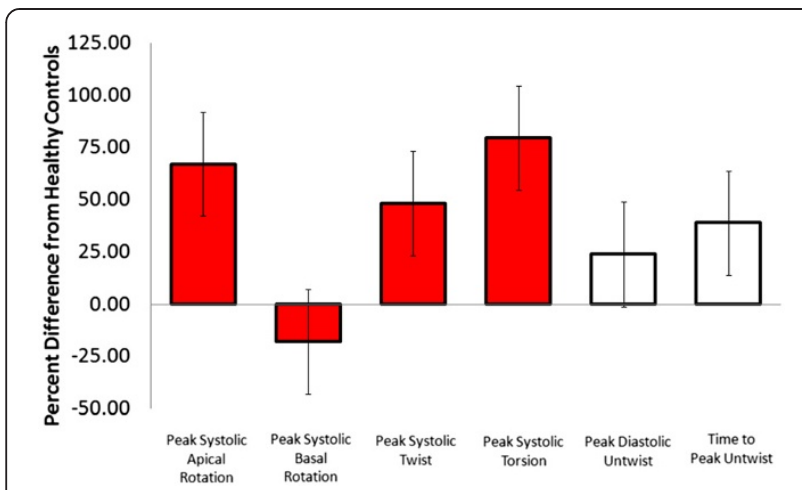

Figure 2 Aortic stenosis - Average percent difference in left ventricular peak systolic apical rotation (Range: Control; 6.8 to 5.7, Patients; 12 to 22.2 degrees),[8,44-46] peak systolic basal rotation (Range: Control; -4.2 to -6.2 , Patients; -2.4 to -6.7 degrees), $[8,45,46]$ peak systolic twist (Range: Control; 8 to 20.8, Patients;12 to 22.2 degrees), $[8,45,46]$ peak systolic torsion (Range: Control; 0.6 to 2.7, Patients; 1.4 to 3.4 degrees/cm), $[8,44]$ peak diastolic untwist (Range: Control; -54.8 to -143 , Patients; -80 to -158 degrees/sec) $[8,44]$ and time to peak untwist (Range: Control; 56 to 115 , Patients; 103 to $115 \mathrm{~ms})[8,46]$ between those with aortic stenosis and healthy controls as reported in existing articles. Systolic parameters denoted by red filled boxes. Diastolic parameters denoted by empty boxes.

together, these results suggest that peak untwist rate may be increased in comparison to age matched controls, however the age related reduction in LV untwist may confound this finding in studies with much younger controls [48]. Finally, three articles reported a prolonged time to peak untwist in those with aortic stenosis $[44,46,47]$, while one article showed no change [8]. The latter article reported that time to peak apical untwist was prolonged but not time to peak basal untwist however, suggesting some sort of disruption in temporal parameters of diastolic rotation.

\section{Conclusions}

The literature shows, from the available moderate strength evidence, that aortic stenosis (LV pressure overload) is associated with an average $75 \%$ increase in systolic apical rotation but very little change (perhaps a small decrease) in basal rotation. It is less clear how diastolic rotation is related to aortic stenosis. It is interesting however that time to peak diastolic untwist was prolonged in aortic stenosis. This may be due to a greater time requirement for peak passive force generation from compressed cardiac spring proteins; owing to greater compression during systole.

\section{Myocardial infarction}

Six published articles investigated LV rotation in those with MI as compared to healthy controls [22,24,49-52]. Downs and Black scores ranged from 14-23 (moderate to strong methodological quality).

\section{Systolic parameters}

Five papers reported a reduction in LV twist $[24,49,51,52]$ or torsion [50] in those with prior MI. Also, four articles reported a decrease in apical rotation in those with MI, although one article by Takeuchi et al. showed no difference [51]. The discrepancy is likely explained more by inclusion criteria than methodological quality as approximately $50 \%$ of MI participants had relatively high ejection fractions (EF) $(>45 \%)$ in Takeuchi's work. When the prior MI group was divided into those with high and low EF, a significant reduction was found for twist and apical rotation in the low EF sub-group only [51]. This relationship between twist and low EF in those with prior MI was confirmed in work by and Govind and colleagues [49]. Similarly, two of the five articles reporting on basal rotation showed a reduction in MI $[49,50]$, whereas three showed no difference between groups (Online Figure 3) [22,51,52]. Although the two articles reporting decreases in basal rotation were of higher methodological quality than the three showing no difference, we feel the discrepancy can be best explained by work by Bansal et al., which showed region of infarct can influence greatly LV rotational dysfunction [50]. For example, the three articles to report no different in systolic basal rotation examined only those with anterior infarction, while the other two articles consisted of a more heterogeneous sample with several regions of infarct.

\section{Diastolic parameters}

Three moderate strength articles which reported on LV rotation in diastole suggest that both untwisting rate and

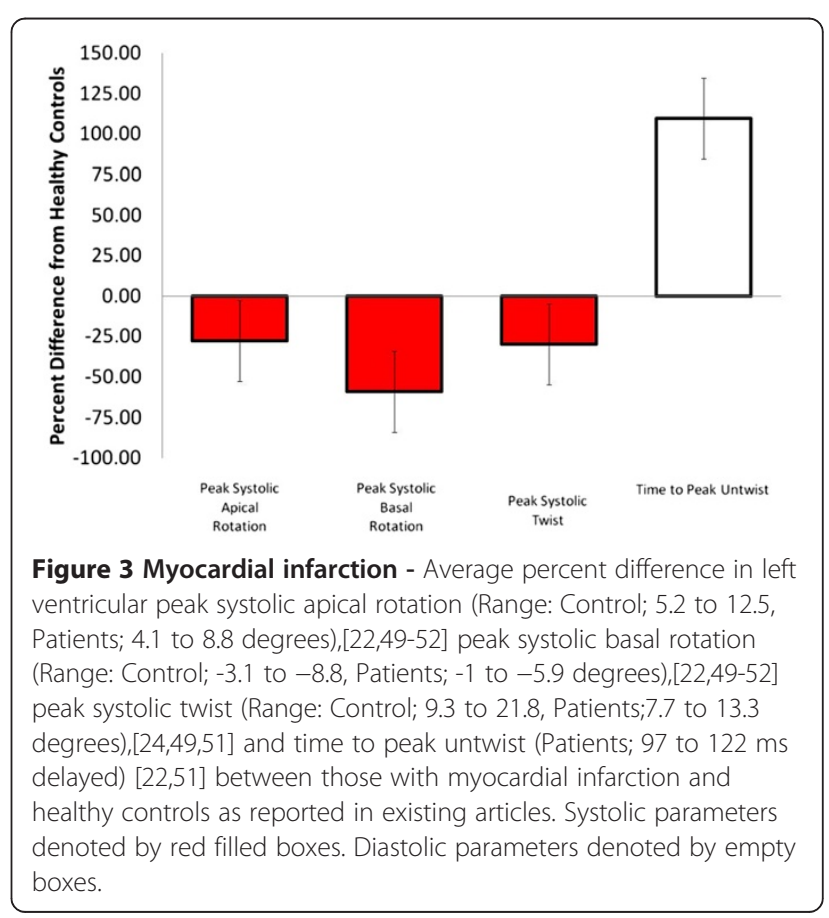


timing are negatively affected by MI. Specifically, two articles showed an increased time to peak untwisting velocity in those with prior MI (Online Figure 3) [22,51], while one article showed that early untwist rate is reduced [52].

\section{Conclusions}

There is moderate to strong level three evidence (somewhat reliable) that rotation characteristics in both systole and diastole are altered in those with prior MI. Specifically, there is agreement in the literature that twist and apical rotation are reduced in MI, however this relationship occurs only when EF is affected by infarction. Also, there is moderately strong evidence that time to peak untwist is longer in those with MI and early untwist rate is reduced; likely the result of systolic-diastolic coupling. Clearly, more work is needed, especially examining LV diastolic rotational parameters in those with MI. Work from Bansal and colleagues highlights a very interesting issue within studies of MI, whereby perhaps global markers of twist and rotation are not suitable for this population unless evaluating differences according to region of infarct [50].

\section{Hypertrophic cardiomyopathy}

Eleven published articles investigated LV rotation in those with HCM as compared to healthy controls [21,23,25,31-33,35,53-56]. One article from this group was a prospective controlled trial (level two evidence) and not a case-control study [25]. Down and Black scores ranged from 10-23 (limited to strong methodological quality).

\section{Systolic parameters}

Those with HCM were widely reported to have no difference in apical rotation $[21,23,31,32,56]$ however two articles showed a significant reduction.[53,55] As the methodological strength was similar for all seven articles, we feel the discrepancies are better explained by methodological differences. The two latter papers were comprised of one article that investigated only those with apical HCM [55] and another which did not report statistics for the difference claimed within the abstract and discussion [53]. In contrast, the five articles which reported no difference in apical rotation were comprised of a relatively heterogeneous group of HCM patients, with accompanying statistical procedures.

A total of seven articles reported on basal rotation in HCM, however two did not report statistics and/or had a small sample size $(n=7$ [23], $n=8$ [53]) while a third investigated only those with apical HCM [55]. Following this, only four were methodologically comparable and valid. These four articles (which had moderate methodological strength, large sample sizes, comparable groups and used STE) consisted of two papers showing an increase in basal rotation $[32,56]$ and two showing no difference $[21,31]$. Of the two articles to show no difference however, one showed a non-significant increasing trend in HCM [21] and the other used a lesser known offline analysis software (velocity vector imaging) [31] which has shown to be only moderately correlated to basal rotation values derived through speckle tracking [57]. As such, we feel the limited available evidence leans towards an increase in basal rotation in those with HCM.

A total of nine articles reported on LV twist in those with HCM Again, the same four papers were methodologically sound and comparable, two of which showed no change in twist, while the same two articles to show no change in basal rotation reported no change in twist $[32,56]$. We again feel the difference could be due to image analysis techniques or possibly subtle differences in sample characteristics such as the ratio of obstructive to non-obstructive HCM patients. It should be noted that Carasso and colleagues used the same sample for both published articles in this section.

\section{Diastolic parameters}

Diastolic LV rotation was shown to be impaired in those with HCM through consistent reports of decreased early untwist rate $[32,55,56]$. Two of these articles specifically reported a reduced percentage of untwist occurring during early diastole $(5 \%, 10 \%$ and $15 \%$ of diastole) in those with HCM (Online Figure 4) [32,56]. Also, two articles described significant reductions in peak untwisting velocity in those with HCM $[55,56]$, while one article with only seven participants showed a non-significant decrease [33]. Finally, average untwist rate was shown to not be different in those with HCM $[33,35]$.

\section{Conclusions}

There is substantial disagreement within the literature examining systolic LV rotation in HCM. It is likely that differences in methodological techniques as well as subtle differences between study populations are the cause of variability in this section, given the extremely heterogeneous nature of HCM phenotypic expression. It appears the disagreement is not due to methodological strength, as even the four strongest articles from this section reported opposite LV twist findings. With such substantial disagreement regarding LV rotation in those with HCM we feel it is not possible, until more work is completed, to comment on overall trends arising from the literature. Diastolic parameters of LV rotation were consistently shown to be impaired in those with HCM.

\section{Dilated cardiomyopathy}

Nine articles examined LV rotation in those with dilated cardiomyopathy as compared to healthy controls 


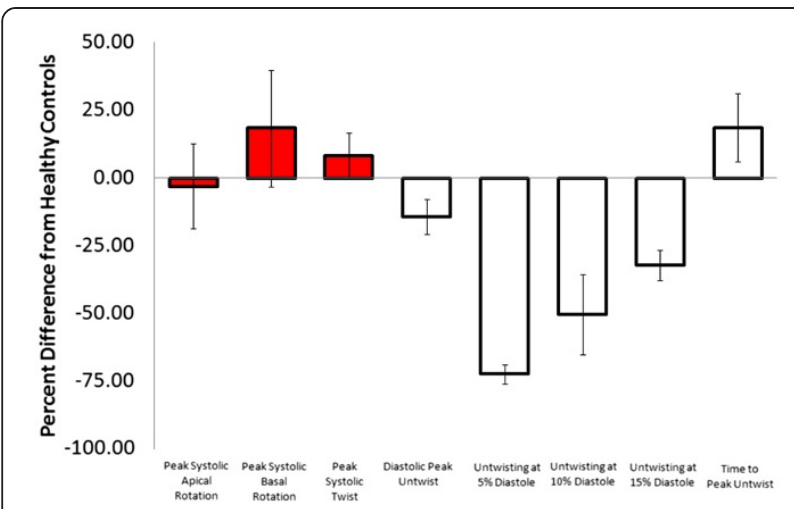

Figure 4 Hypertrophic cardiomyopathy - Average percent difference in left ventricular peak systolic apical rotation (Range: Control; 3.6 to 19.5 , Patients; 4.1 to 12 degrees),[21,31-33,56] peak systolic basal rotation (Range: Control; -3.4 to -8.1 , Patients; -3.2 to -6.6 degrees),[21,31-33,56] peak systolic twist (Range: Control; 6.6 to 22.6, Patients; 7 to 20 degrees) $[21,23,32,33,55,56]$, untwisting at $5 \%$ diastole (Range: Control; 17 to 21, Patients; 10 to 12 percent),[32,56] untwisting at $10 \%$ diastole (Range: Control; 35 to 37, Patients; 23 to 25 percent),[32,56] untwisting at 15\% diastole (Range: Control; 49 to 50, Patients; 36 to 39 percent)[32,56] and time to peak untwist (Range: Control; 14.6 to 111, Patients; 22.8 to $153 \%$ of systole (lower values normalized for diastolic duration) $[55,56]$ between those with hypertrophic cardiomyopathy and healthy controls as reported in existing articles. Diastolic parameters denoted by empty boxes. Note that one author used the same population in two publications. $[31,54]$ Therefore only one article was used in the percentage difference calculations.[31] Systolic parameters denoted by red filled boxes. Diastolic parameters denoted by empty boxes.

[7,30,34-36,58-61]. Down and Black scores ranged from 15-19 (moderate methodological quality).

\section{Systolic parameters}

Nine articles examined systolic LV rotation in those with dilated cardiomyopathy [7,30,34-36,58-61]. All articles to report these parameters were in agreement that apical rotation, LV twist [7,30,34-36,58-61] and torsion $[7,30,34,61]$ were reduced (Online Figure 5). Of the nine papers that reported systolic basal rotation, seven showed a reduction while two reported no difference in those with dilated cardiomyopathy. Both articles that did not show a significant difference in basal rotation were completed by the same author, contained relatively small sample sizes $(\mathrm{n}=10)$ and included only participants who had restrictive LV filling (not a criteria in the other articles) $[36,60]$. Of the three articles that reported on time to peak twist, two showed a significant increase in duration in the dilated cardiomyopathy group $[58,61]$ while one paper showed no difference [36]. This latter article was one of the articles with modified inclusion criteria [36]. Lastly, it was consistently reported that large proportions of those with dilated cardiomyopathy have reverse rotation in either the apex or base $[7,30,58]$.

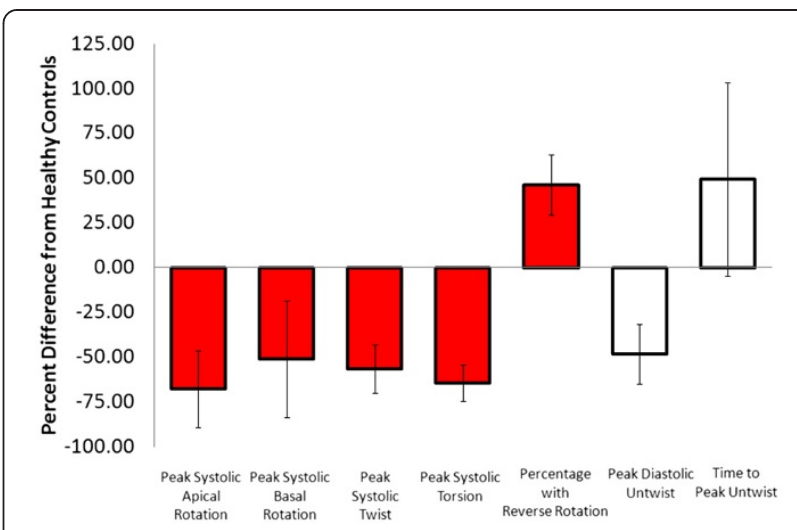

Figure 5 Dilated cardiomyopathy - Average percent difference in left ventricular peak systolic apical rotation (Range: Control; 5.4 to

15.8, Patients; 0.1 to 5.9 degrees),[7,30,34,36,58-61] peak systolic basal rotation (Range: Control; -2.6 to -7.1 , Patients; -3.2 to -6.6 degrees), [7,30,34,36,58-61] peak systolic twist (Range: Control; 9.8 to 17 , Patients; 4 to 7.35 degrees),[7,34,36,58-61] peak systolic torsion (Range: Control; 1.7 to 3, Patients; 0.4 to 1.3 degrees/cm),[7,34] percentage with reverse rotation, $[7,30,58]$ peak diastolic untwist (Range: Control; -86 to -113 , Patients; -37 to -62 degrees) $[34,35,59,60]$ and time to peak untwist $[59,60]$ between those with dilated cardiomyopathy and healthy controls as reported in existing articles. Systolic parameters denoted by red filled boxes. Diastolic parameters denoted by empty boxes.

\section{Diastolic parameters}

All articles which reported on diastolic LV rotational parameters in those with dilated cardiomyopathy were in agreement that average and peak untwisting velocity was significantly decreased $[34,35,59,60]$, while time to peak untwist was increased $[59,60]$.

\section{Conclusions}

There is broad agreement, according to level three evidence (somewhat reliable), that systolic and diastolic ventricular rotation characteristics are reduced in those with dilated cardiomyopathy. Also there was agreement in all three articles where it was reported, implying that the LV rotates similar to a rotating pipe, instead of twisting sponge, in those with dilated cardiomyopathy.

\section{Non-compaction}

Two articles investigated LV rotational parameters in those with non-compaction cardiomyopathy as compared to healthy controls and received D\&B scores of 17 [36] and 19 [62] (moderate methodological quality).

\section{Systolic parameters}

Bellavia and colleagues reported a reduction in apical rotation and twist as well as twist rate in a grouped sample of non-compaction participants [62]. When looking at a subgroup of non-compaction with normal EF, basal rotation was not different, but in a reduced $\mathrm{EF}(<50 \%)$ subgroup basal rotation was reduced [62]. Work by van 
Dalen also reported a reduction in apical rotation and LV twist in those with non-compaction [36]. Interestingly, van Dalen reported that rotation in all those with non-compaction was in the same direction at the apex and base, instead of opposite directions as in healthy controls. Roughly half non-compaction participants reported LV rotation in the counterclockwise direction at both the apex and base, while the other half reported clockwise rotation [36].

\section{Diastolic parameters: None reported Conclusions}

There is level three evidence (somewhat reliable) that systolic LV rotational parameters are reduced in those with non-compaction cardiomyopathy $[36,62]$. The evidence suggests that the LV rotates in unison at the base and apex resulting in very little twist [36]. A figure was not created for non-compaction, as groups were not comparable between articles.

\section{Systolic heart failure}

Five articles investigated LV rotation in those with SHF as compared to matched controls [20,43,63-65]. Heart failure was diagnosed according to standards from the New York Heart Association (class III or IV) $[43,63,64]$ or the Heart Failure and Echocardiography Associations of the European Society of Cardiology [20], while one article did not report specific criteria (however did report an EF of $26 \%$ in their clinical population) [65]. Downs and Black scores ranged from 17-23 (moderate to strong methodological quality).

\section{Systolic parameters}

The three articles that reported on systolic apical and basal rotation were in agreement showing a reduction in both regions in SHF $[43,64,65]$ (Online Figure 6). Similarly, all articles that reported on LV twist in those with systolic heart failure showed significant reductions $[20,43,63,65]$. Finally, one article reported that $59 \%$ of SHF patients had reversed rotation at either the basal or apical level [63].

\section{Diastolic parameters}

The one article to report on LV diastolic rotation parameters in those with SHF showed apical untwisting was reduced while basal untwisting was not different [65].

\section{Conclusions}

There is level three evidence (somewhat reliable) that systolic LV rotation is altered in those with SHF. There is also level three evidence (somewhat reliable) that diastolic apical untwisting is altered in those with SHF. It appears that apical and basal rotation occurs in unison in a high proportion of those with SHF. More work is

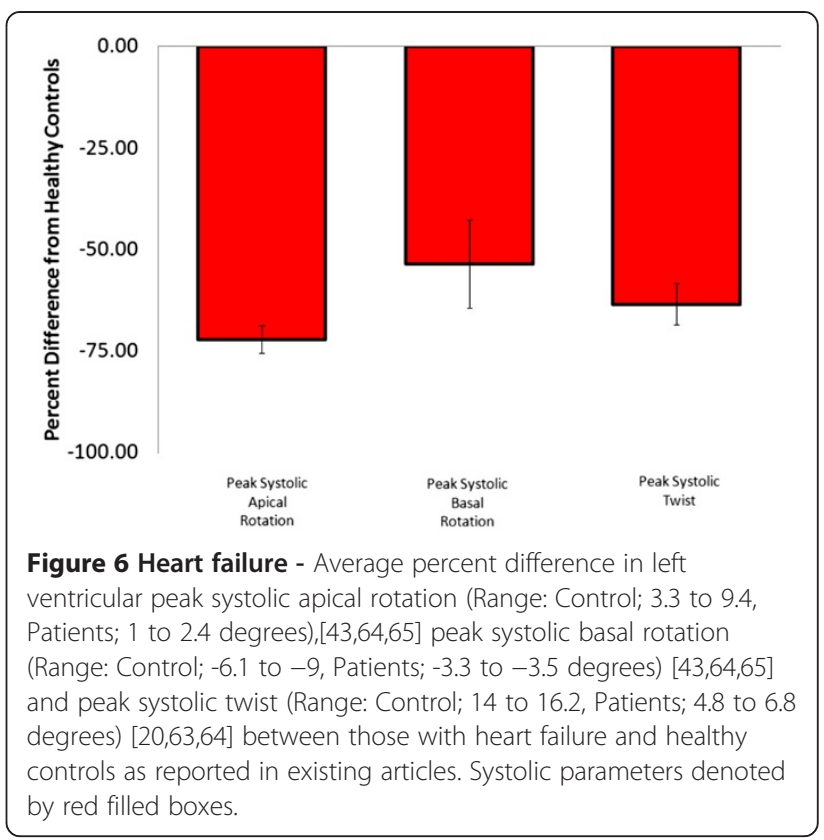

needed to clarify diastolic rotational motion of the LV in those with SHF.

\section{Diastolic Dysfunction/Heart Failure Normal Ejection Fraction}

Heart failure normal ejection (HFnEF) fraction describes a significant reduction in LV filling during diastole (diastolic dysfunction), with a preserved EF. Diastolic dysfunction is described by four categories of increasing intensity, with HFnEF considered grades three and four as long as EF is preserved [66]. Left ventricle rotation in those with diastolic dysfunction as compared to healthy controls were examined by six published articles [3,20,37,67-69]. Downs and Black scores ranged from 17-23 (moderate to strong methodological quality).

\section{Systolic parameters}

The five articles to report on systolic LV rotation in those with diastolic dysfunction have considerable disagreement between studies. Work by Park and colleagues reported a significant increase in apical rotation, basal rotation, twist and twist rate in those with grade one diastolic dysfunction (impaired relaxation), while those with more severe diastolic dysfunction were not different from controls [3]. Similarly, Mizuguchi et al. reported a reduction in twist rate as well as a trend toward reduced twist in participants with mild diastolic dysfunction (impaired relaxation) [37]. At first glance, these findings appear to be in opposition to the other articles which reported no difference in LV rotation between groups $[20,67,68]$.

These disagreements can likely be explained by systolic LV rotation differing across the spectrum of diastolic 
dysfunction, as EF was preserved in all articles. Park and colleagues as well as Mizuguchi et al. only reported significant differences between the control group and those with the mildest form of diastolic dysfunction (impaired relaxation) whereas the two more severe categories were not different from those of controls regarding systolic LV rotation. In support of this contention, the only other article to look at an intermediate diastolic dysfunction group showed borderline significant increases in apical rotation $(P=0.07)$ and twist $(P=0.18)$, with no difference in the more severe diastolic dysfunction group. [68] Considering the available evidence, the literature supports the notion that systolic rotation is increased in those with mild diastolic dysfunction but normalizes in more severe stages of disease.

\section{Diastolic parameters}

A relatively small number of articles reported diastolic LV rotation in those with diastolic dysfunction. $[3,67,68]$ Park and colleagues showed that untwist rate was increased in those with grade one diastolic dysfunction. Also two articles reported that those with moderate diastolic dysfunction, untwist rate [3] and time to peak untwist [67] were not different than those of controls. Further, Park et al. showed that those with grade three diastolic dysfunction had untwisting rates less than those found in healthy controls. Finally, Perry et al. showed that peak early diastolic apical untwist was reduced further with increases in grade of diastolic function [69]. Again, it appears from the literature that diastolic LV rotation is increased in those with moderate diastolic dysfunction but reduces as severity of disease increases.

\section{Conclusions}

There is level three evidence (somewhat reliable) that LV rotation in both systole and diastole is increased in those with mild diastolic dysfunction (Online Figure 7). Further to this, there is level three evidence (somewhat reliable) to suggest that LV systolic rotation is not different from health controls in more severe stages of disease $[3,37,68]$. More work is needed to clarify diastolic LV rotation in different stages of diastolic dysfunction however it appears that diastolic rotation is increased in mild, similar in moderate and reduced in severe diastolic dysfunction as compared to healthy controls.

\section{Combined categories}

Several heart diseases have been investigated by a single article and are discussed here in unison in the interest of readability. The individual ranking and other specific details for each article can be reviewed in Table 7 (Online). Pacemaker implantation [70], and constrictive pericarditis [29] all had reduced systolic rotation while those with heart transplants [5], restrictive cardiomyopathy

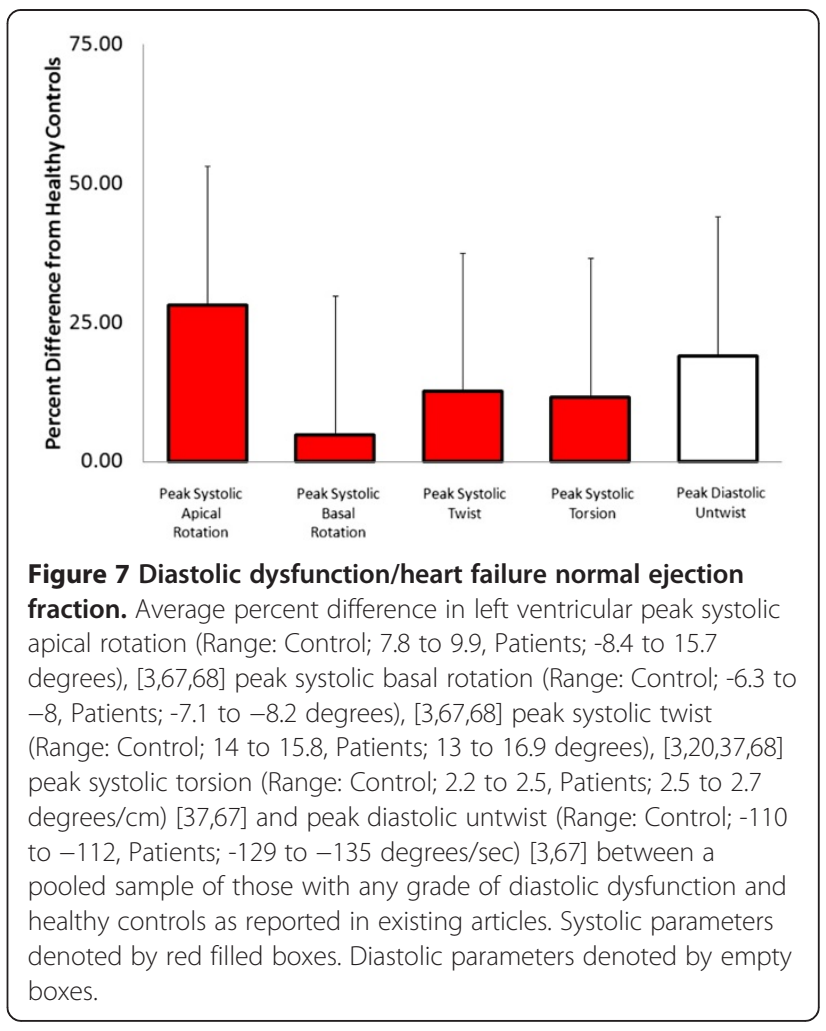

[29] and cardiovascular risk factors [37] did not. The only article from this group to report diastolic parameters showed no difference between heart transplant recipients and healthy recipient-aged and donor-aged controls. Interestingly, heart transplant recipients did have significantly reduced twist and peak untwist rate during exercise but not at rest [5]. Paetsch et al. examined LV rotation in patients with coronary artery disease showing apical systolic rotation and diastolic apical untwisting was reduced at both high and low dobutamine doses while time to peak untwist was reduced in comparison to healthy controls in the low dose only [71].

\section{Discussion}

The purpose of this review was to compile and evaluate relevant literature examining the difference between those with various heart diseases and healthy individuals with regard to LV rotation. Due to ethical limitations to inducing disease in the human model, study design throughout the review is almost entirely comprised of level three evidence. Although this limitation is valid, a large cohort study design that follows participants from the relatively healthy early years of life, to later life when heart disease is apparent, would provide level two evidence, and aid in the understanding of the sequence of LV rotation abnormalities in various heart disease states. Unfortunately, it is outside the scope of this systematic 
review to comprehensively discuss underling mechanisms responsible for each change in LV rotation although brief summaries have been provided in each conclusion paragraph.

Taking into consideration the available evidence (heart diseases with more than one published article which contain quantified numeric outcome values), it appears that aortic stenosis as well as SHF and dilated cardiomyopathy lead to the most profound changes in LV systolic rotation as compared to healthy controls. According to the same criteria, in diastole, MI, HCM and dilated cardiomyopathy have the largest reductions in LV rotational parameters. Interestingly, aortic stenosis has considerable support showing systolic rotation is increased as compared to healthy controls. It is also worth note that there are no trends in the literature suggesting systolicdiastolic rotational uncoupling in heart disease.

In an effort to provide clinical meaning, it appears from the literature that heart disease with heterogeneous characterization such as MI and HCM show less agreement in relationship to parameters of LV rotation. To our knowledge no literature exists regarding the prognostic value of LV rotation. In light of the reports found in this article, there may be clinical value in monitoring LV rotation in those at the highest risk for aortic stenosis with no other clinical markers of LV dysfunction, as well as untwist in those with suspected diastolic dysfunction.

Several studies did not utilize relevant control groups, matched on known cardiovascular confounding factors such as age (See Tables 2, 3, 4, 5, 6, 7, 8 for specific details). This shortcoming is most apparent in articles investigating heart diseases occurring late in life, possibly due to the perceived relative difficulty in recruiting control volunteers in their mid sixties as compared to those in a younger age group. We encourage authors to be diligent in regard to appropriate matching of controls. If matched-groups are not possible, statistical procedures such as analysis of co-variance (ANCOVA) should be employed to better evaluate the independent effect of the specific heart disease in question. We did find however, that other important confounders such as gender, blood pressure, LV mass, LV volume, and EF were relatively well matched or accounted for throughout. Another common shortcoming in the literature is the widespread omittance of data reporting the duration of time participants have been diagnosed with a given disease, which would improve our understanding of the pathological sequences.

There is considerable variability in the context of terminology used to describe LV rotation between journal articles. For example, torsion is commonly used to define twist and vice versa, while twist in some articles is instead used to describe basal or apical rotation. Moreover, several different measures of diastolic rotation are employed throughout the literature. Most commonly, untwist rate is reported however some authors prefer early untwist rate, untwist rate at 5\%,10\%, and 25\% of diastole, while still others report apical untwisting rate. Taking care to standardize parameters in this relatively new practice of measuring LV rotation may increase the rate at which the field progresses, by allowing similar studies to directly compare results.

Finally, exercise has been shown to be a powerful tool for increasing the sensitivity of tests designed to diagnose LV functional changes. In light of this we feel further studies should employ, when possible, an exercise stimulus while examining differences in LV function in those with heart disease. Where it has been reported, exercise has exaggerated differences in LV rotation between healthy and diseased hearts $[5,25]$. The evaluation of LV rotational motion has been studied during exercise with relative success at sub-maximal exercise intensities [72].

Several limitations exist in this systematic review which we have made efforts to mitigate through our study design. Firstly, there is evidence that significant variability exists between and within and between speckle-tracking software [73]. We have attempted to control for this in our summary figures by calculating the percent difference between controls and heart disease groups for each article, and averaging the results. This will at least ensure that differences in absolute values are not compared between articles which may not have comparable absolute results. Detailed recommendations for moving forward in this line of research to ensure comparability between studies have been recently published [73]. It is well known that heart diseases are not mutually exclusive and often more than two or more heart diseases are present in a given patient. For this reason we acknowledge that many of the subjects included in the reviewed articles may have had other heart diseases and significant overlap between values may have occurred. In any case, we feel the overall findings do shed light on trends in LV rotational changes occurring in a group with a common principle heart disease. Also, although the vast majority of articles imaged apical and basal rotation according to the standard landmarks, there may be some variability between studies which employed different short axis levels of apical rotation; resulting in more mid-level oriented images. We have tried to account for this by reporting the short axis images collected by each study in the comprehensive tables (Online Supplement Tables 3, 4, 5, 6, 7, 8, 9). As a final point, it should be mentioned that one article has shown three-dimensional STE to be more sensitive to changes in LV rotation occurring due to heart disease [74]. Additional articles on this topic are required to corroborate this finding but an early assumption would be 
that 2D-STE may underestimate some measures of LV rotation in those with heart disease.

\section{Conclusions}

Left ventricular rotation parameters in those with various heart diseases are not commonly investigated in comparison to healthy controls but can add important insight into LV functional changes occurring during heart disease progression. This is likely due to the novel and time-consuming nature of the measurement techniques. Specifically, heart transplant, pacemaker implantation and pericardial abnormalities have a glaring shortage of available literature comparing with healthy controls. According to the available literature, LV rotation in both systole and diastole are altered in various forms of heart disease. The various parameters commonly measured (i.e., apical rotation, untwist rate) appear to follow their own disease-dependent pattern.

\section{Competing interests}

The authors declare that they have no competing interest.

\section{Acknowledgments}

Special recognition is given to Dr. Charlesworth for her expertise regarding the development of systematic reviews of the literature.

\section{Author details}

${ }^{1}$ Experimental Medicine Program, Faculty of Medicine, University of British Columbia, Vancouver, Canada. ${ }^{2}$ Physical Activity and Chronic Disease Prevention Unit, University of British Columbia, Vancouver, Canada. ${ }^{3} \mathrm{Rm}$. 205, Unit II Osborne Centre, 6108 Thunderbird Blvd, University of British Columbia, Vancouver, BC V6T 1Z3, Canada.

\section{Authors' contributions}

AAP conceptualized the topic, performed the literature search, drafted the manuscript and edited the manuscript. ATC independently performed the literature search and edited the manuscript. SSDB conceptualized the topic and edited the manuscript. DERW conceptualized the topic and edited the manuscript. All authors read and approved the final manuscript.

\section{Funding}

This research was supported by funding from the Canadian Institutes of Health Research, the Michael Smith Foundation for Health Research, the Natural Sciences and Engineering Research Council of Canada, the Canada Foundation for Innovation and the BC Knowledge Development Fund. AA Phillips was supported by funding from Natural Sciences and Engineering Research Council and the Mathematics of Information and Complex Systems. DER Warburton was supported by salary awards from the Canadian Institutes of Health Research and the Michael Smith Foundation for Health Research.

Received: 11 January 2012 Accepted: 24 June 2012

Published: 24 June 2012

\section{References}

1. Han W, Xie MX, Wang XF, et al: Assessment of left ventricular torsion in patients with anterior wall myocardial infarction before and after revascularization using speckle tracking imaging. Chin Med J (Engl) 2008, 121(16):1543-1548.

2. Tanaka H, Oishi $Y$, Mizuguchi $Y$, et al: Contribution of the pericardium to left ventricular torsion and regional myocardial function in patients with total absence of the left pericardium. J Am Soc Echocardiogr 2008, 21(3):268-274.

3. Park SJ, Miyazaki C, Bruce CJ, et al: Left ventricular torsion by two-dimensional speckle tracking echocardiography in patients with diastolic dysfunction and normal ejection fraction. J Am Soc Echocardiogr 2008, 21(10):1129-1137.
4. Esch BT, Scott JM, Haykowsky MJ, et al: Changes in ventricular twist and untwisting with orthostatic stress: endurance athletes versus normally active individuals. J App/ Physiol 2010, 108(5):1259-1266.

5. Esch BT, Scott JM, Warburton DE, et al: Left ventricular torsion and untwisting during exercise in heart transplant recipients. J Physiol 2009, 587(Pt 10):2375-2386.

6. Esch BT, Warburton DE: Left ventricular torsion and recoil: implications for exercise performance and cardiovascular disease. J Appl Physiol 2009, 106(2):362-369.

7. Meluzin J, Spinarova L, Hude P, et al: Left ventricular mechanics in idiopathic dilated cardiomyopathy: systolic-diastolic coupling and torsion. J Am Soc Echocardiogr 2009, 22(5):486-493.

8. Popescu BA, Calin A, Beladan CC, et al: Left ventricular torsional dynamics in aortic stenosis: relationship between left ventricular untwisting and filling pressures. A two-dimensional speckle tracking study. Eur J Echocardiogr 2010, 11(5):406-413.

9. Helle-Valle T, Crosby J, Edvardsen T, et al: New noninvasive method for assessment of left ventricular rotation: speckle tracking echocardiography. Circulation 2005, 112(20):3149-3156.

10. Notomi Y, Lysyansky P, Setser RM, et al: Measurement of ventricular torsion by two-dimensional ultrasound speckle tracking imaging. J Am Coll Cardiol 2005, 45(12):2034-2041.

11. Notomi $Y$, Setser RM, Shiota T, et al: Assessment of left ventricular torsional deformation by Doppler tissue imaging: validation study with tagged magnetic resonance imaging. Circulation 2005, 111(9):1141-1147.

12. Cho GY, Chan J, Leano R, et al: Comparison of two-dimensional speckle and tissue velocity based strain and validation with harmonic phase magnetic resonance imaging. Am J Cardiol 2006, 97(11):1661-1666.

13. Russel IK, Gotte MJ, Bronzwaer JG, et al: Left ventricular torsion: an expanding role in the analysis of myocardial dysfunction. JACC CardiovasC Imaging 2009, 2(5):648-655.

14. Arts T, Reneman RS: Dynamics of left ventricular wall and mitral valve mechanics-a model study. J Biomech 1989, 22(3):261-271.

15. Fukuda N, Sasaki D, Ishiwata S, et al: Length dependence of tension generation in rat skinned cardiac muscle: role of titin in the FrankStarling mechanism of the heart. Circulation 2001, 104(14):1639-1645.

16. Helmes M, Lim CC, Liao R, et al: Titin determines the Frank-Starling relation in early diastole. J Gen Physiol 2003, 121(2):97-110.

17. Cameli M, Ballo P, Righini FM, et al: Physiologic determinants of left ventricular systolic torsion assessed by speckle tracking echocardiography in healthy subjects. Echocardiography 2011, 28(6):641-648.

18. Dong SJ, Hees PS, Huang WM, et al: Independent effects of preload, afterload, and contractility on left ventricular torsion. Am J Physiol 1999, 277(3 Pt 2):H1053-1060.

19. Biederman RW, Doyle M, Yamrozik J, et al: Physiologic compensation is supranormal in compensated aortic stenosis: does it return to norma after aortic valve replacement or is it blunted by coexistent coronary artery disease? An intramyocardial magnetic resonance imaging study. Circulation 2005, 112(9 Suppl):1429-1436.

20. Wang J, Khoury DS, Yue $Y$, et al: Preserved left ventricular twist and circumferential deformation, but depressed longitudinal and radial deformation in patients with diastolic heart failure. Eur Heart J 2008, 29(10):1283-1289.

21. Abozguia K, Nallur-Shivu G, Phan TT, et al: Left ventricular strain and untwist in hypertrophic cardiomyopathy: relation to exercise capacity. Am Heart J 2010, 159(5):825-832.

22. Nagel $E$, Stuber $M$, Lakatos $M$, et al: Cardiac rotation and relaxation after anterolateral myocardial infarction. Coron Artery Dis 2000, 11(3):261-267.

23. Young AA, Kramer CM, Ferrari VA, et al: Three-dimensional left ventricular deformation in hypertrophic cardiomyopathy. Circulation 1994, 90(2):854-867.

24. Garot J, Pascal O, Diebold B, et al: Alterations of systolic left ventricular twist after acute myocardial infarction. Am J Physiol Heart Circ Physiol 2002, 282(1):H357-H362.

25. Notomi Y, Martin-Miklovic MG, Oryszak SJ, et al: Enhanced ventricular untwisting during exercise: a mechanistic manifestation of elastic recoil described by Doppler tissue imaging. Circulation 2006, 113(21):2524-2533.

26. Eng JJ, Teasell RJ, Miller WC, Wolfe DL, Townson AF, Aubut J, Abramson C, Hsieh JTC, Connolly S, Konnyu K: Spinal Cord Injury Rehabilitation Program: Method of the SCIRE Systematic Review. Topics in Spinal Cord Injury 2007, :1-10. 
27. Sackett DL, Rosenberg WMC, Gray JAM, Haynes BR, Richardson WS: Evidence based medicine: what it is and what it isn't. British Medical Journal 1996, 312:71-72.

28. Krassioukov A, Warburton DE, Teasell $R$, et al: A systematic review of the management of autonomic dysreflexia after spinal cord injury. Arch Phys Med Rehabil 2009, 90(4):682-695.

29. Sengupta PP, Krishnamoorthy VK, Abhayaratna WP, et al: Disparate patterns of left ventricular mechanics differentiate constrictive pericarditis from restrictive cardiomyopathy. JACC Cardiovasc Imaging 2008, 1(1):29-38.

30. Popescu BA, Beladan CC, Calin A, et al: Left ventricular remodelling and torsional dynamics in dilated cardiomyopathy: reversed apical rotation as a marker of disease severity. Eur J Heart Fail 2009, 11(10):945-951.

31. Carasso S, Yang H, Woo A, et al: Systolic myocardial mechanics in hypertrophic cardiomyopathy: novel concepts and implications for clinical status. J Am Soc Echocardiogr 2008, 21(6):675-683.

32. van Dalen BM, Kauer F, Soliman Ol, et al: Influence of the pattern of hypertrophy on left ventricular twist in hypertrophic cardiomyopathy. Heart 2009, 95(8):657-661.

33. Wang J, Buergler JM, Veerasamy K, et al: Delayed untwisting: the mechanistic link between dynamic obstruction and exercise tolerance in patients with hypertrophic obstructive cardiomyopathy. J Am Coll Cardiol 2009, 54(14):1326-1334.

34. Liu X, Li Z: Assessment of cardiac twist in dilated cardiomyopathy using velocity vector imaging. Echocardiography 2010, 27(4):400-405.

35. Buakhamsri A, Popovic ZB, Lin J, et al: Impact of left ventricular volume/ mass ratio on diastolic function. Eur Heart J 2009, 30(10):1213-1221.

36. van Dalen BM, Caliskan K, Soliman Ol, et al: Left ventricular solid body rotation in non-compaction cardiomyopathy: a potential new objective and quantitative functional diagnostic criterion? Eur J Heart Fail 2008, 10(11):1088-1093.

37. Mizuguchi $Y$, Oishi $Y$, Miyoshi $H$, et al: The functional role of longitudinal, circumferential, and radial myocardial deformation for regulating the early impairment of left ventricular contraction and relaxation in patients with cardiovascular risk factors: a study with two-dimensional strain imaging. J Am Soc Echocardiogr 2008, 21(10):1138-1144.

38. Hartling L, Brison RJ, Crumley ET, et al: A systematic review of interventions to prevent childhood farm injuries. Pediatrics 2004 114(4):e483-e496.

39. Hignett S: Systematic review of patient handling activities starting in lying, sitting and standing positions. J Adv Nurs 2003, 41(6):545-552.

40. Hing W, Bigelow R, Bremner T: Mulligan's Mobilization with Movement: A Systematic Review. The Journal of Manual \& Manipulative Therapy 2008, 27:E39-E66.

41. Carasso S, Cohen O, Mutlak D, et al: Differential effects of afterload on left ventricular long- and short-axis function: insights from a clinical model of patients with aortic valve stenosis undergoing aortic valve replacement. Am Heart J 2009, 158(4):540-545.

42. Tzemos N, Silversides CK, Carasso S, et al: Effect of pregnancy on left ventricular motion (twist) in women with aortic stenosis. Am J Cardiol 2008, 101(6):870-873.

43. Zhang Q, Fung JW, Yip GW, et al: Improvement of left ventricular myocardial short-axis, but not long-axis function or torsion after cardiac resynchronisation therapy: an assessment by two-dimensional speckle tracking. Heart 2008, 94(11):1464-1471.

44. Stuber M, Scheidegger MB, Fischer SE, et al: Alterations in the local myocardial motion pattern in patients suffering from pressure overload due to aortic stenosis. Circulation 1999, 100(4):361-368.

45. Sandstede JJ, Johnson T, Harre K, et al: Cardiac systolic rotation and contraction before and after valve replacement for aortic stenosis: a myocardial tagging study using MR imaging. AJR Am J Roentgenol 2002, 178(4):953-958.

46. Nagel E, Stuber M, Burkhard B, et al: Cardiac rotation and relaxation in patients with aortic valve stenosis. Eur Heart J 2000, 21(7):582-589.

47. van Dalen BM, Tzikas A, Soliman OI, et al: Left ventricular twist and untwist in aortic stenosis. Int J Cardiol 2011, 148(3):319-324.

48. Zhang $Y$, Zhou QC, Pu DR, et al: Differences in left ventricular twist related to age: speckle tracking echocardiographic data for healthy volunteers from neonate to age 70 years. Echocardiography 2010, 27(10):1205-1210.

49. Govind SC, Gadiyaram VK, Quintana M, et al: Study of left ventricular rotation and torsion in the acute phase of ST-elevation myocardial infarction by speckle tracking echocardiography. Echocardiography 2010, 27(1):45-49

50. Bansal M, Leano RL, Marwick TH: Clinical assessment of left ventricular systolic torsion: effects of myocardial infarction and ischemia. J Am Soc Echocardiogr 2008, 21(8):887-894.

51. Takeuchi M, Nishikage $T$, Nakai $H$, et al: The assessment of left ventricular twist in anterior wall myocardial infarction using two-dimensional speckle tracking imaging. J Am Soc Echocardiogr 2007, 20(1):36-44.

52. Setser RM, Smedira NG, Lieber ML, et al: Left ventricular torsional mechanics after left ventricular reconstruction surgery for ischemic cardiomyopathy. J Thorac Cardiovasc Surg 2007, 134(4):888-896.

53. Maier SE, Fischer SE, McKinnon GC, et al: Evaluation of left ventricular segmental wall motion in hypertrophic cardiomyopathy with myocardial tagging. Circulation 1992, 86(6):1919-1928

54. Carasso S, Yang H, Woo A, et al: Diastolic myocardial mechanics in hypertrophic cardiomyopathy. J Am Soc Echocardiogr 2010, 23(2):164-171.

55. Chang SA, Kim HK, Kim DH, et al: Left ventricular twist mechanics in patients with apical hypertrophic cardiomyopathy: assessment with 2D speckle tracking echocardiography. Heart 2010, 96(1):49-55.

56. van Dalen BM, Kauer F, Michels $M$, et al: Delayed left ventricular untwisting in hypertrophic cardiomyopathy. J Am Soc Echocardiogr 2009 22(12):1320-1326

57. Kim DH, Kim HK, Kim MK, et al: Velocity vector imaging in the measurement of left ventricular twist mechanics: head-to-head one way comparison between speckle tracking echocardiography and velocity vector imaging. J Am Soc Echocardiogr 2009, 22(12):1344-1352.

58. Sade LE, Demir O, Atar I, et al: Effect of mechanical dyssynchrony and cardiac resynchronization therapy on left ventricular rotational mechanics. Am J Cardio/ 2008, 101(8):1163-1169.

59. Saito M, Okayama $H$, Nishimura $K$, et al: Determinants of left ventricular untwisting behaviour in patients with dilated cardiomyopathy: analysis by two-dimensional speckle tracking. Heart 2009, 95(4):290-296.

60. van Dalen BM, Soliman OI, Vletter WB, et al: Left ventricular untwisting in restrictive and pseudorestrictive left ventricular filling: novel insights into diastology. Echocardiography 2010, 27(3):269-274.

61. Kanzaki H, Nakatani S, Yamada N, et al: Impaired systolic torsion in dilated cardiomyopathy: reversal of apical rotation at mid-systole characterized with magnetic resonance tagging method. Basic Res Cardiol 2006, 101(6):465-470.

62. Bellavia D, Michelena HI, Martinez M, et al: Speckle myocardial imaging modalities for early detection of myocardial impairment in isolated left ventricular non-compaction. Heart 2010, 96(6):440-447.

63. Russel IK, Gotte MJ, de Roest GJ, et al: Loss of opposite left ventricular basal and apical rotation predicts acute response to cardiac resynchronization therapy and is associated with long-term reversed remodeling. J Card Fail 2009, 15(8):717-725.

64. Bertini M, Marsan NA, Delgado $V$, et al: Effects of cardiac resynchronization therapy on left ventricular twist. J Am Coll Cardiol 2009, 54(14):1317-1325.

65. Fuchs $\mathrm{E}$, Muller MF, Oswald $\mathrm{H}$, et al: Cardiac rotation and relaxation in patients with chronic heart failure. Eur J Heart Fail 2004, 6(6):715-722

66. Khouri SJ, Maly GT, Suh DD, et al: A practical approach to the echocardiographic evaluation of diastolic function. J Am Soc Echocardiogr 2004, 17(3):290-297.

67. Phan TT, Shivu GN, Abozguia K, et al: Left ventricular torsion and strain patterns in heart failure with normal ejection fraction are similar to agerelated changes. Eur J Echocardiogr 2009, 10(6):793-800.

68. Jang HS, Kim JH, Bae BS, et al: Characteristics of myocardial deformation and rotation in subjects with diastolic dysfunction without diastolic heart failure. Korean Circ J 2009, 39(12):532-537.

69. Perry R, De Pasquale CG, Chew DP, et al: Assessment of early diastolic left ventricular function by two-dimensional echocardiographic speckle tracking. Eur J Echocardiogr 2008, 9(6):791-795

70. Delgado V, Tops LF, Trines SA, et al: Acute effects of right ventricular apical pacing on left ventricular synchrony and mechanics. Circ Arrhythm Electrophysiol 2009, 2(2):135-145.

71. Paetsch I, Foll D, Kaluza A, et al: Magnetic resonance stress tagging in ischemic heart disease. Am J Physiol Heart Circ Physiol 2005, 288(6): $\mathrm{H} 2708-\mathrm{H} 2714$

72. Stohr EJ, Gonzales-Alonso J, Shave R: Left ventricular mechanical limitations to stroke volume in healthy humans during incremental 
exercise. American Journal of Physiology - Heart and Circulatory Physiology 2011, 301:H478-H487.

73. Kaul S, Miller JG, Grayburn PA, et al: A suggested roadmap for cardiovascular ultrasound research for the future. J Am Soc Echocardiogr 2011, 24(4):455-464.

74. Maffessanti F, Nesser HJ, Weinert $L$, et al: Quantitative evaluation of regional left ventricular function using three-dimensional speckle tracking echocardiography in patients with and without heart disease. Am J Cardiol 2009, 104(12):1755-1762.

doi:10.1186/1471-2261-12-46

Cite this article as: Phillips et al:: Heart disease and left ventricular rotation - a systematic review and quantitative summary. BMC Cardiovascular Disorders 2012 12:46

\section{Submit your next manuscript to BioMed Central and take full advantage of:}

- Convenient online submission

- Thorough peer review

- No space constraints or color figure charges

- Immediate publication on acceptance

- Inclusion in PubMed, CAS, Scopus and Google Scholar

- Research which is freely available for redistribution 